\title{
Multifractal Analysis of Soil Surface Roughness
}

\author{
R. García Moreno, M. C. Díaz Álvarez, A. Saa Requejo, and A. M. Tarquis
}

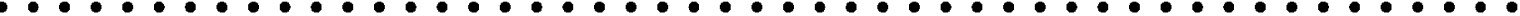
Soil surface roughness (SSR) is a parameter highly suited to the study of soil susceptibility to wind and water erosion. The development of a methodology for quantifying SSR is therefore instrumental to soil evaluation. We developed such a method, based on the multifractal analysis (MFA) of soil elevation measurements collected at the intersections on a $2-$ by $2-\mathrm{cm}^{2}$ grid in a 200 - by $200-\mathrm{cm}^{2}$ plot. Samples were defined using the gliding box algorithm (GB), in which a box of a given size "glides" across the grid map in all possible directions. The advantage of the GB over the box counting algorithm is that it yields a greater number of large sample sizes, which usually leads to better statistical results. Standard deviation, semivariogram fractal dimension, and semivariogram crossover length were estimated for all scenarios to compare the results of SSR multifractal analysis to indices found with traditional techniques. For its high sensitivity to the spatial arrangement implicit in a data set, MFA appears to be better suited than classical indices to compare plots tilled under different management criteria. The results showed that MFA is able to effectively reflect the heterogeneity and complexity of agricultural SSR. Based on this type of analysis, two new indices have been defined to compare the multifractal spectrum characteristics of the raw data to the characteristics of a random field with the same average and SD.
\end{abstract}

ABBreviations: GB, gliding box algorithm; MFA, multifractal analysis; MFS, multifractal spectrum; RD, random data set; SMV, semivariogram; SSR, soil surface roughness.

$\mathbf{C}$ OIL SURFACE ROUGHNESS (SSR), which describes the microvariation in soil elevations across a field resulting primarily from tillage practices and soil texture, is one of the major factors in wind and water erosion (Porta Casanellas et al., 2003). Soil surface roughness and the complementary soil microrelief depression pattern determine water infiltration and drainage network development (Vidal Vázquez et al., 2006). Most studies on SSR have focused on the mathematical description of the variations appearing after rainfall to predict water infiltration and runoff (Linden and Van Doren, 1986; Kamphorst et al., 2000; Darboux and Huang, 2003).

Soil surface roughness is defined as the standard deviation of surface elevation readings. After tillage, soil microtopography exhibits randomly oriented tillage roughness marks of different sizes as well as clods (Allmaras et al., 1966; Zobeck and Onstad,

R. García Moreno, M.C. Díaz Álvarez, and A. Saa Requejo, Soil Science and Climatology, School of Agricultural Engineering, Polytechnic Univ. of Madrid, Ciudad Universitaria s.n. Madrid 28040, Spain; A.M. Tarquis, Applied Mathematics, School of Agricultural Engineering, Polytechnic Univ. of Madrid, Ciudad Universitaria s.n. Madrid 28040, Spain. Received 17 Jan. 2007. Corresponding author (chgarcia@terra.es).
1987; Huang, 1998). Each specific tillage tool creates its own oriented roughness pattern, which is relatively easy to quantify using a simple geometric model. The challenge consists in quantifying the spatial distribution of randomly oriented SSR (Huang, 1998).

Soil surface roughness, taken on a scale ranging from centimeters to millimeters, plays a very important role in increasing water infiltration and the amount of crop water available and in reducing runoff on cultivated lands (Podmore and Huggins, 1981; Armstrong, 1986; Kamphorst et al., 2000). At the same time, it is an important factor in predicting wind erosion (Zobeck, 1991; Larney et al., 1995), one of the main forms of soil degradation in semiarid and arid climates. The concomitant loss of organic matter and nutrient-rich topsoil occasions a decline in soil productivity (Hagen, 1988; Potter et al., 1990; Larney et al., 1998). Soil surface roughness quantification is therefore crucial to understanding soil erosive processes and how soil properties are altered by human action, primarily tillage (Perfect et al., 1990; Larney et al., 1999; Saxton, 1995; Murillo et al., 2004).

During the past few years, SSR analysis has focused on developing a unified conceptual framework for describing the geometric complexity of the data with the aid of fractal parameters. A number of methods have been proposed to estimate the fractal dimensions of soil microtopography (Linden and Van Doren, 1986; Malinverno, 1990; Perfect and Kay, 1995; Vidal Vázquez et al., 2005, 2006). The fractal techniques used can be divided into two groups: nonvariational and variational. Nonvariational techniques implicitly assume soil surface self-similarity across a range of scales and aim to characterize soil microrelief features by calculating a single index. Because microrelief fractal behavior is 
better modeled on the basis of either self-similar or prefractal surfaces, the use of nonvariational techniques has been highly criticized, which has in turn encouraged the use of variational methods (Vivas Miranda, 2000; Vidal Vázquez et al., 2005). The first group includes tortuosity (Bertuzzi et al., 1990) and the Richardson number (Gallart and Pardini, 1996; Pardini and Gallart, 1998). The second group of methods, in turn, is comprised of the semivariogram method (Armstrong, 1986; Huang and Bradford, 1992; Eltz and Norton, 1997; Vivas Miranda, 2000; Vivas Miranda and Paz González, 2002), spectral analysis (Burg, 1967), and the several existing versions of the root mean square or roughness length method (Malinverno, 1990; Gallant et al., 1994; Vivas Miranda, 2000; Vivas Miranda and Paz González, 2002).

Variational techniques are considered to provide a better description of SSR (Vidal Vázquez et al., 2006, 2007). The ones most commonly used to estimate the fractal indices of soil profiles or surfaces are semivariance and local root mean square. Both of these methods are based on the calculation of the Hurst exponent, $H$, from which the fractal dimension, $D$, is assessed; moreover, variational methods involve an additional parameter, the so-called crossover length, $l$. The fractal dimension, $D$, is a descriptor of horizontal variations in soil roughness, whereas $l$ is related to vertical differences in point elevation data (Vidal Vázquez et al., 2006).

In addition, multifractal models have been used to analyze the scale-invariant properties of objects in very different domains, from turbulent flows to financial data. Scale invariance has been found to be of increasing importance in understanding the complexity of natural phenomena. Multifractal analysis (MFA) has been used intensively in geomorphometry or digital terrain heights (digital elevation models) (Pike, 2000), but only recently to study agricultural soils. Manninen (2003) showed that bare soil exhibits multiscale behavior and Roisin (2007) that MFA can effectively analyze the variability in the inner heterogeneity of tilled soils from soil strength measurements.

Based on the foregoing, the present study aimed to apply the most common SSR techniques, standard deviation and semivariogram, and compare and evaluate the results obtained with the results of MFA. To this end, several soil types and tillage tools were selected to study heterogeneity based on soil height readings.

\section{Materials and Methods}

\section{Experimental Sites}

The field experiments were conducted on different soil types at three sites in semiarid central Spain (N36 $00^{\prime} 00^{\prime \prime}-$ $\mathrm{N} 43^{\circ} 45^{\prime} 00^{\prime \prime}$ and $\mathrm{W} 9^{\circ} 30^{\prime} 00^{\prime \prime}-\mathrm{E} 4^{\circ} 30^{\prime} 00^{\prime \prime}$. The first experimental plot was located in the province of Madrid, in fields belonging to the Polytechnic University of Madrid's School of Agricultural Engineering (the Madrid site). The other two were located at La Higueruela (Santa Olalla, province of Toledo), in the Spanish National Research Council's Experimental Station for Environmental Science (La Higueruela site). The main soil characteristics, tested according to ISRIC/FAO (Merrill, 1995) and
Soil Science Society of America (Sparks, 1996) methodologies, are given in Table 1.

The three types of tools used to till each soil type, namely chisel plow, moldboard plow, and roller, are the three most common in the central regions of Spain. All measurements were taken immediately after tillage to preclude the effects of other factors. In other words, SSR was analyzed in a total of nine scenarios. Tillage was performed using John Deere equipment: a Model 2810 moldboard plow, a Model 610 integral chisel plow, and a roller level.

The field data were gathered in 2005, one of the driest seasons in Spain in the last $100 \mathrm{yr}$, with no rainfall recorded in either the spring or the summer. Indeed, while the average annual rainfall in the area is $411 \mathrm{~mm}$, only $125 \mathrm{~mm}$ fell in the experimental region between 1 Sept. 2004 and 31 Aug. 2005 (Instituto Nacional de Meteorologia, www.inm.es/; verified 22 Feb. 2008).

\section{Soil Surface Roughness Data}

Field microtopography measurements were obtained with a full-scale pin meter (Fig. 1). This instrument consisted of a row of $35-\mathrm{cm}$-high pins, placed in a frame in which they could slide up or down to conform to surface irregularities. The pin heads were marked with a blue band to better visualize their respective positions when in contact with the soil. The frame, $85 \mathrm{~cm}$ high in all, was designed to be able to move the instrument across the soil without disturbing the pin pattern. The instrument was made of lightweight aluminum for ease of handling. With rows containing 50 pins spaced at $20-\mathrm{mm}$ intervals, one full meter could be measured along the $x$ axis with each reading. The $y$ axis readings were taken by sliding the instrument across the plot, on tracks, stopping at $20-\mathrm{mm}$ intervals. As the cells on the resulting grid measured 20 by $20 \mathrm{~mm}$, a total of 2500 readings were taking per $1.0 \mathrm{~m}^{2}$ of area. An earlier study (García Moreno, 2006) showed

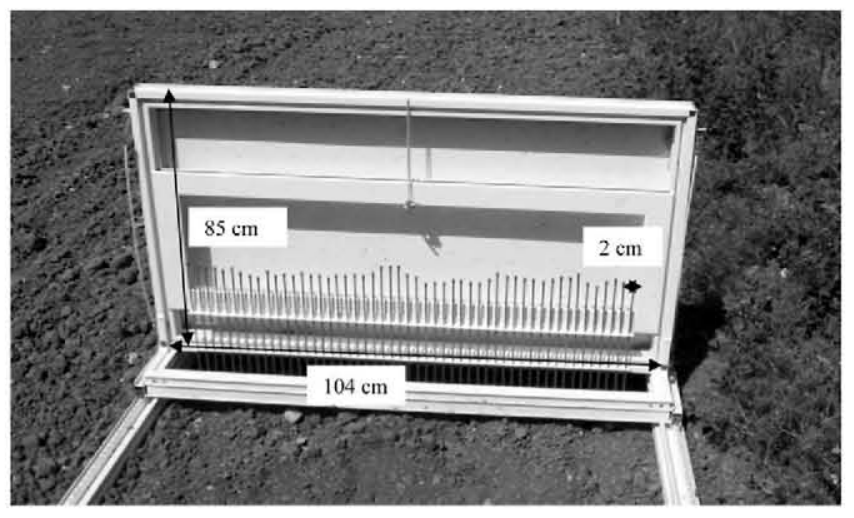

Fig. 1. Pin meter developed to capture soil surface roughness data at the field level. 
this spacing to be sufficient to measure the surface roughness of the three types of soil.

Each corner of the instrument was marked with a red dot and Visual Basic software was developed that would detect these marks as the vertical and horizontal references for shifts in row position.

A Kodak DC 4800 digital camera, set on a tripod, was used to capture pin positions. The lens was focused on a point at the center of the pin meter, i.e., at the average height of the red marks, to ensure the image would not be distorted. After comparing several models, a Silk tripod was found to be best suited to the 40-cm camera height required. The 3.1-megapixel camera was fitted with a $3 \times(28-84)$ optical zoom lens.

Since each plot, randomly chosen across a tilled area measuring 5 by $10 \mathrm{~m}^{2}$, was divided into four $1.0-\mathrm{m}^{2}$ subplots, the effects of each soil type and tillage tool were measured on four subplots. The data gathered were statistically analyzed to compare the effects of the different tools and soil types studied.

The field procedure consisted in placing the pin meter on the surface of a $1.0-\mathrm{m}^{2}$ patch of soil and capturing the initial pin positions and the positions after each $20-\mathrm{mm}$ shift along the $y$ axis. The camera was initially placed at a distance of $2 \mathrm{~m}$ from the pin meter. The $x$ axis measurements were the positions of the row of 50 pins. The instrument was moved along the $y$ axis over two rails perforated at 20 -mm intervals. It was fitted with a hand brake to halt the process when soil was suspected to be on a light grade.

Consequently, the area measured was 2 by $2 \mathrm{~m}^{2}$, with a resolution of 20 by $20 \mathrm{~mm}^{2}$. A total of 10,000 elevation readings were taken on each field surface, sufficient to estimate SSR indices and perform MFA (Merel and Farres, 1998; Tarquis et al., 2003). Photographs of the nine scenarios studied, after tillage, are shown in Fig. 2.

A random data set $(\mathrm{RD})$ was generated by randomly extracting 10,000 numbers from a normal distribution function having the same mean and standard deviation (first and second moments of the raw data) as the SSR original data. The semivariance was

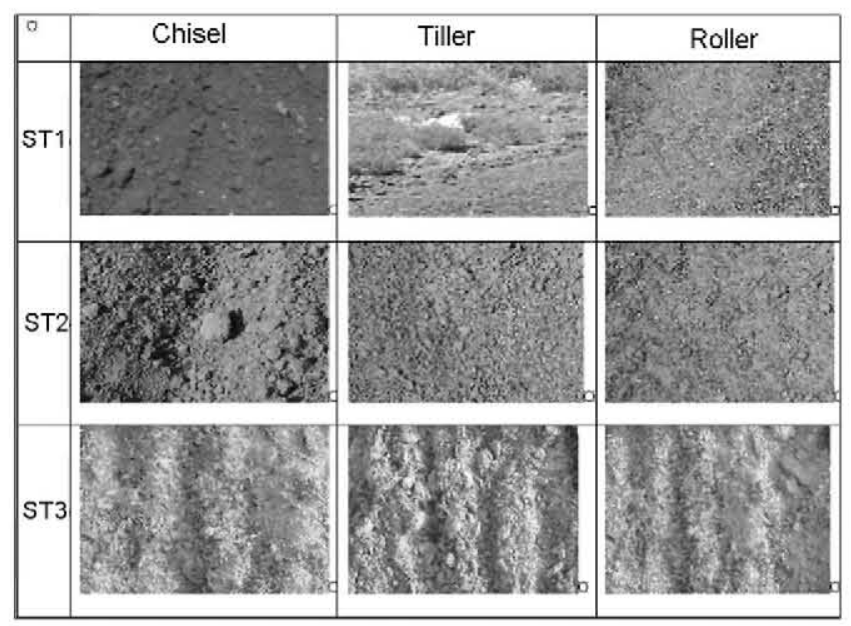

FIG. 2. Images of the plots after cultivation with a chisel plow (left), a moldboard plow (center), or a roller (right) for the experimental fields at the Polytechnic University of Madrid, with a sandy clay loam soil (ST1), La Higueruela (C.S.I.C.) with a sandy clay loam soil (ST2), and La Higueruela (C.S.I.C.) with a sandy loam soil (ST3). calculated for all RDs to verify that these random data exhibited no spatial structure.

\section{Soil Surface Roughness Index}

According to a bibliographic review conducted by Kamphorst et al. (2000), one of the most common indices used in such studies is the random roughness index (Allmaras et al., 1966; Currence and Lovely, 1970). Since this index constitutes the standard deviation of a line parallel to the direction of tillage, however, and the aim of this study was to evaluate soil surface roughness for the entire area, it is termed SD (standard deviation) here. The $S D$ index reflects both random and oriented soil roughness and is calculated as

$$
\mathrm{SD}=\sqrt{\frac{1}{N-1} \sum_{i=1}^{N}\left[Z\left(x_{i}\right)-\bar{Z}\right]^{2}}
$$

where $x_{i}$ is point elevation measurement $i, Z(x)$ is the elevation at location $x, \bar{Z}$ is the average value of set $\left\{Z\left(x_{i}\right)\right\}$ and $N$ is the number of data points (10,000 in this study).

\section{Semivariogram Analysis}

This technique, first introduced by Burrough (1983) to study variability in soil properties, has since been applied to quantify SSR by a number of researchers (Armstrong, 1986; Huang and Bradford, 1992; Kamphorst et al., 2000; Vivas Morales and Paz González, 2002; Vidal Vázquez et al., 2005).

Unlike the SD index, a semivariogram (SMV) characterizes the spatial correlation of point elevation measurements $x_{i}$. Semivariogram $\gamma(h)$ is defined as follows:

$\gamma(h)=\frac{1}{2 N(h)} \sum_{i=1}^{N(h)}\left[Z\left(x_{i+h}\right)-Z\left(x_{i}\right)\right]^{2}$

where $h$ is the lag distance between points and $N(b)$ is the number of pairs considered.

The log-log plot of $\gamma(h)$ vs. $h$ is linear for most soil surface elevations up to a certain distance from the origin (crossover length), as in fractal Brownian motion models (Huang and Bradford, 1992; Huang, 1998; Vivas Miranda and Paz González, 2002; Vidal Vázquez et al., 2005). In such cases, the semivariogram fractal dimension $\left(D_{\mathrm{SMV}}\right)$ and semivariogram crossover length $\left(l_{\mathrm{SMV}}\right)$ can be determined from the slope, $H$ (Hurst exponent), and the $y$ intercept, $\alpha$, of the semivariogram vs. lag distance $\log -\log$ plot (see Huang and Bradford, 1992, for a full discussion):

$D_{\mathrm{SMV}}=3-H$

$l_{\mathrm{SMV}}=\exp \left(\frac{a}{2-2 H}\right)$

In the present study, the semivariogram method was used to characterize self-similar SSR via two parameters, $D_{\mathrm{SMV}}$ and $l_{\mathrm{SMV}}$, for each soil and tillage tool.

\section{Multifractal Analysis}

An MFA was conducted to determine whether SSR data spatially decompose into an infinite number of intertwined sets of fractal dimensions. In that case, since one fractal dimension cannot embody all the complexity involved, several fractal dimen- 
sions must be estimated, depending on the position. Then $Z(x)$ may be interpreted to be a measure that can be standardized as follows:

$$
\mu_{i}=\frac{Z\left(x_{i}\right)}{\sum_{j=1}^{N} Z\left(x_{j}\right)}
$$

"Up-scaling" partitioning in the box counting method yields the partition function $\chi(q, \delta)$ defined by Feder (1989) as

$\chi(q, \delta)=\sum_{i=1}^{N(\delta)} \mu_{i}^{q}(\delta)=\sum_{i=1}^{N(\delta)} m_{i}^{q}$

where $m$ is the mass of the measure, $q$ is the mass exponent, $\delta$ is the box length, and $N(\delta)$ is the number of boxes, with $m_{i}>0$. On that basis, the mass exponent function $\tau(q)$ shows how the moment of the mass scales with box size:

$$
\begin{aligned}
\langle\tau(q)\rangle & =\lim _{\delta \rightarrow 0} \frac{\log \langle\chi(q, \delta)\rangle}{\log (\delta)} \\
& =\lim _{\delta \rightarrow 0} \frac{\log \left\langle\sum_{i=1}^{N(\delta)} m_{i}^{q}\right\rangle}{\log (\delta)}
\end{aligned}
$$

where \langle\rangle represents the statistical moment of the measure $\mu_{i}(\delta)$ defined in a group of nonoverlapping boxes of the same size into which the area studied is partitioned.

The singularity index $(\alpha)$ can be determined by a Legendre transformation of the $\tau(q)$ curve (Evertsz and Mandelbrot, 1992), as in the following expression:

$$
\langle\alpha(q)\rangle=\frac{\mathrm{d}\langle\tau(q)\rangle}{\mathrm{d} q}
$$

The number of cells of size $\delta$ with the same $\alpha, N_{\alpha}(\delta)$, is related to cell size as $N_{\alpha}(\delta) \propto \delta^{-f(\alpha)}$, where $f(\alpha)$ is the scaling exponent of the cells having a common $\alpha$. Parameter $f(\alpha)$ can be calculated as

$$
\langle f(\alpha)\rangle=q\langle\alpha(q)\rangle-\langle\tau(q)\rangle
$$

The multifractal spectrum (MFS), which plots $\alpha$ vs. $f(\alpha)$, quantitatively characterizes the right-left asymmetric variability of the measure studied, thereby indicating the predominance of small or large values, respectively, and can be described by

$$
\begin{aligned}
& \Delta f\left(\alpha_{\max }\right)=f[\alpha(0)]-f\left[\alpha\left(q_{\min }\right)\right] \\
& \Delta f\left(\alpha_{\min }\right)=f[\alpha(0)]-f\left[\alpha\left(q_{\max }\right)\right]
\end{aligned}
$$

The MFS width $\left(w_{\alpha}\right)$ is a reflection of overall variability (Tarquis et al., 2001) and may be expressed as

$w_{\alpha}=\alpha_{\max }-\alpha_{\min }$

Estimating MFS is no easy task and a number of researchers have reported the errors and difficulties that may arise depending on the range of values, the resolution, and the partitioning algorithm used (Buczhowski et al., 1998; Bird et al., 2006; Perrier et al., 2006). In light of the small number of measurements available for applying this type of analysis compared with studies in other domains, the gliding box method was chosen instead of the box counting method (Grau et al., 2006). Originally designed for lacunarity analysis (Allain and Cloitre, 1991), the gliding box method was subsequently modified by Cheng $(1997 \mathrm{a}, \mathrm{b})$ for use in MFA (Grau et al., 2006). This method constructs samples essentially by gliding a square box with sides of a certain size $(\delta)$ over the grid map in all possible directions. In the partitioning process, the minimum size of each side $\left(\delta_{\text {min }}\right)$ is "up-scaled" to a predetermined size, which must in any event be smaller than the total length $(L)$ of the plot, i.e., $2 \mathrm{~m}$ in the present study. Proportionally, the number of boxes with sides measuring $\delta$ $\left[N^{*}(\delta)\right]$ is

$$
N^{*}(\delta) \propto\left(\frac{L}{\delta_{\min }}-r+1\right)^{2}
$$

where $\delta_{\min } \leq \delta \leq L$ and $r$ is the ratio of the side of the box and to the minimum size chosen $\left(\delta / \delta_{\text {min }}\right)$.

Since the partitioning process involves overlapping, the measure defined by these boxes is not statistically independent. Consequently, the definition of the measure differs with each box size. Letting $N^{*}(m, \delta)$ be the number of gliding boxes of size $\delta$ and mass $m$, dividing by $N^{*}(\delta)$ yields the probability function $\beta(m, \delta)$ for a gliding box of size $\delta$ and mass $m$. The statistical moment of this distribution is (Cheng, 1999)

$$
\begin{aligned}
\chi^{*}(q, \delta) & =\sum_{m} \beta(m, r) m^{q} \\
& =\frac{1}{N^{*}(\delta)} \sum_{i=1}^{N^{*}(\delta)} m_{i}^{q}(\delta)-\mathrm{E}\left\{m^{q}\right\}
\end{aligned}
$$

where $\chi^{*}(q, \delta)$ is the $q$ th order moment of $\beta(m, \delta)$ and the summation encompasses all the gliding boxes with $m_{i}>0$. The difference between $\chi^{*}(q, \delta)$ and the statistical moments of the distribution in the box counting method $[\chi(q, \delta)]$ is that

$$
\chi(q, \delta)-\left(\frac{L}{\delta}\right)^{2} \mathrm{E}\left\{m^{q}\right\}
$$

Combining Eq. [14] and [15],

$$
\chi(q, \delta)-\left(\frac{L}{\delta}\right)^{2} \chi^{*}(q, \delta)
$$

Substituting this expression in Eq. [7] (Cheng, 1997a) yields

$$
\langle\tau(q)\rangle=\lim _{r \rightarrow 0} \frac{\log \left\langle\chi^{*}(q, \delta)\right\rangle}{\log (\delta)}-2=\left\langle\tau^{*}(q)\right\rangle-2
$$

where 2 is the number of dimensions of the Euclidean plane supporting the data.

Equations [8] and [9] can now be rewritten as

$$
\begin{aligned}
\langle\alpha(q)\rangle & =\frac{\mathrm{d}\left\langle\tau^{*}(q)\right\rangle}{\mathrm{d} q}=\left\langle\alpha^{*}(q)\right\rangle \\
\langle f(\alpha)\rangle & =q\left\langle\alpha^{*}(q)\right\rangle-\left\langle\tau^{*}(q)\right\rangle+2 \\
& =\left\langle f^{*}(\alpha)\right\rangle+2
\end{aligned}
$$

In the present study, the multiplier method was used to estimate $\tau^{*}(q)$ (Cheng, 1999):

$$
\left\langle\tau^{*}(q)\right\rangle=-\frac{\log [\langle M(q, \delta)\rangle]}{\log (r)}
$$


where $M$ represents the multiplier measured at each data point as

$M(q, \delta)=\left[\frac{\mu\left(\delta_{\min }\right)}{\mu(\delta)}\right]^{q}$

The advantage of using Eq. [20] and [21] is that $T(q)$ may be estimated with successive box sizes because the estimate is independent of box size $\delta$. Pursuant to Eq. $[21], \mu\left(\delta_{\min }\right)$ may not be nil; otherwise the ratio $\mu\left(\delta_{\min }\right) / \mu(\delta)$ would always be 0 or undefined, regardless of the value of $\delta$.

Equations [20] and [21] can be used to obtain $\langle\alpha(q)\rangle$ and $\langle f(\alpha)>$ (Cheng, 1997a, 1999):

$\langle\alpha(q)\rangle=-\frac{\left\langle M(q, \delta)^{q} \log [M(q, \delta)]\right\rangle}{\left\langle M(q, \delta)^{q}\right\rangle \log (r)}$

$\langle f(q)\rangle=2+$

$\frac{\left\langle M(q, \delta)^{q}\right\rangle \log \langle M(q, \delta)\rangle-q\left\langle M(q, \delta)^{q} \log [M(q, \delta)]\right\rangle}{\left\langle M(q, \delta)^{q}\right\rangle \log (r)}$

The following assumptions were adopted for the MFAs conducted on this data set: (i) the value of $q$ ranged from -5 to 5 , with increments of 0.5 ; and (ii) in all linear regression estimates of $\langle\alpha(q)\rangle$ and $\langle f(\alpha)\rangle$, the $R^{2}$ value had to be $>0.98$.

Several researchers (Schertzer and Lovejoy, 1991; Cheng and Agterberg, 1996; Agterberg et al., 1996) have used the curvatures of functions $\alpha(q), \tau(q)$, and $f(q)$ to test the degree of multifractality. Cheng and Agterberg (1996), for instance, analyzed $\tau(q)$ linearity around $q=1$ to differentiate a multifractal from a fractal or nonfractal measure. In this study, we adopted a more intuitive approach to this question by comparing the spectrum obtained with the original data to the one obtained with an unstructured RD. Mathematically, where $f(\alpha)=2$, the MFS obtained with a RD should ultimately be limited to a single point. As the number of RDs is small, however, the MFS may deviate from theoretical behavior (Ahammer and DeVaney, 2005).

\section{Results}

Soil Roughness Indexes

The results obtained from the SSR indices are consistent with the photographs in Fig. 2. The SD values for all nine SSR scenarios are shown in Table 2 . The highest SD values were obtained for the sandy clay loam, the soil type prevailing at the Madrid site. These fields, characterized by a high incidence of clods and fragmented stones, have been tilled conventionally for many years. The pedogenic influence is greater in the more highly developed La Higueruela site soils, where conservation tillage has been in place for the last $20 \mathrm{yr}$.

The tillage tool yielding the highest SD index was the chisel plow, followed by the moldboard plow and roller. An exception to this rule arose in the sandy clay loam at La Higueruela, where the soil was so dry that chisel plowing was nearly ineffectual. This difficulty was not encountered with the other tools, which work at shallower depths.

\section{Semivariogram Analysis}

Almost all the semivariances followed a similar pattern, exhibiting two straight lines on the log-log diagram (see Fig. 3A as an example of the results) that slope steeply at short distances
TABLE 2. Standard deviation (SD), semivariogram fractal dimension $\left(D_{\mathrm{SMV}}\right)$, and semivariogram crossover length $\left(I_{\mathrm{SMV}}\right)$ for soil surface roughness, semivariogram model range, and number of lags in the variogram $(N)$ calculated for three tillage tools and the following soils: a sandy clay loam at Madrid (ST1); a sandy clay loam at La Higueruela (ST2); and a sandy loam at La Higueruela (ST3).

\begin{tabular}{llccccc}
\hline \multirow{2}{*}{ Soil } & \multirow{2}{*}{ Tillage tool } & SD & \multicolumn{4}{c}{ Semivariogram } \\
\cline { 4 - 6 } & & mm & & \multicolumn{2}{c}{$D_{\text {SMV }}$} & \multicolumn{2}{c}{$I_{\text {SMV }}$} & Range & $N$ \\
\hline \multirow{2}{*}{ ST1 } & Chisel & 16.0 & 2.9 & 274 & 600 & 30 \\
& Moldboard plow & 8.90 & 2.9 & 348 & 600 & 30 \\
& Roller & 6.60 & 2.9 & 242 & 500 & 25 \\
ST2 & Chisel & 3.50 & 2.7 & 160 & 1000 & 50 \\
& Moldboard plow & 5.90 & 2.9 & 250 & 960 & 48 \\
& Roller & 3.00 & 2.5 & 66 & 400 & 20 \\
\multirow{2}{*}{ ST3 } & Chisel & 3.30 & 2.5 & 100 & 620 & 31 \\
& Moldboard plow & 2.42 & 2.6 & 46 & 680 & 34 \\
& Roller & 1.87 & 2.7 & 52 & 560 & 28 \\
\hline
\end{tabular}

and taper for lag distances of $>60 \mathrm{~cm}$. Such patterns must be interpreted to mean that in these cases, depending on the range of lag distances for which linear regression is performed, different $D_{\mathrm{SMV}}$ values may be obtained. The variations in the $D_{\mathrm{SMV}}$ value imply that in some cases a single dimension is insufficient to describe the complexity of the measure studied (SSR in this case) and are a first indication of the multifractal nature of SSR.

Regression analyses were run for all the semivariances, increasing the lag distance as necessary to reach $R^{2}$ values $<0.98$. Given the small scales studied, these distances ranged from 40 to $100 \mathrm{~cm}$ (Table 2).

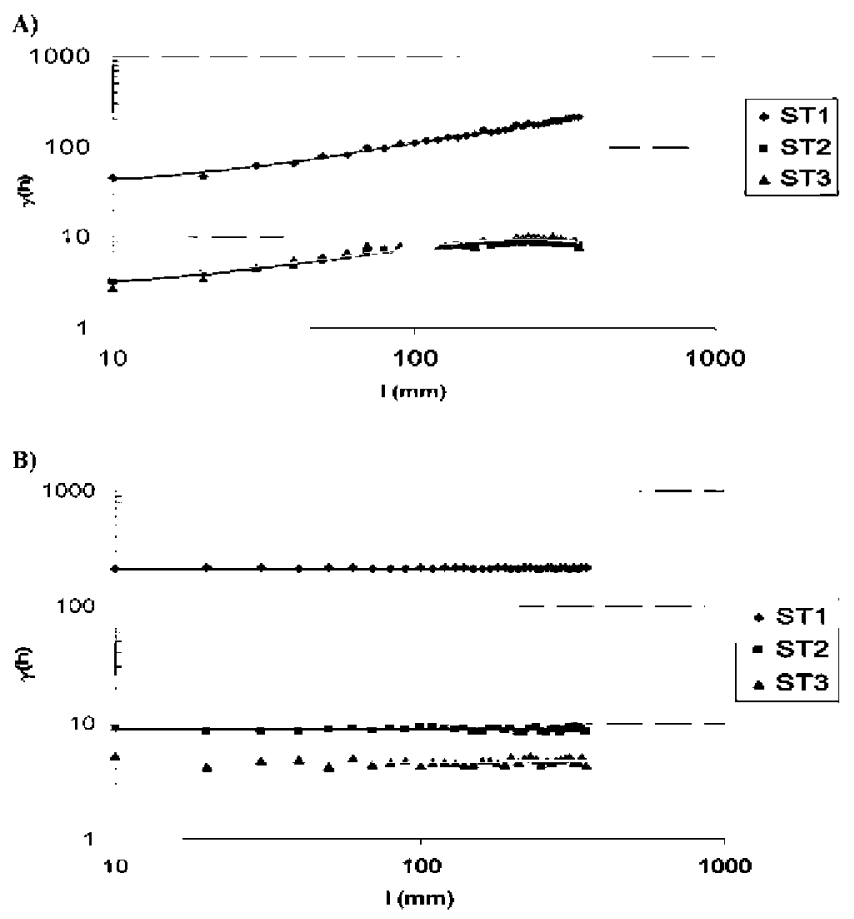

FIG. 3. Semivariograms of the soil surface roughness distribution after chisel plowing a sandy clay loam soil at the Polytechnic University of Madrid (ST1), a sandy clay loam at La Higueruela (ST2), and a sandy loam at La Higueruela (ST3): (A) real and (B) random data have been used in the semivariograms of SSR. The lines correspond to best-fit linear regression for the fractal model of Huang and Bradford (1992). 
The pattern exhibited by all the semivariances for the random data (Fig. 3B) signifies a lack of spatial structure. This finding provides the grounds for comparing the effect of SSR spatial arrangement, depending on tillage tool and soil type, with MFA.

As a general rule, $l_{\mathrm{SMV}}$ was higher for the Madrid site than for the other two experimental fields. When the two plots with a similar soil texture (sandy clay loam) were compared, the highest $l_{\text {SMV }}$ was found for the moldboard plow, which accounted, on the contrary, for the lowest value in the sandy loam plot. The differences among the three tillage tools and their effects were reflected more distinctly with $l_{\mathrm{SMV}}$ than with $D_{\mathrm{SMV}}$.

\section{Multifractal Analysis}

Soil surface roughness proved to be clearly multifractal in some cases, as Fig. 4 shows, with the $\tau(q)$ for the original data curving convexly, as opposed to the straight line obtained for the random data.

The multifractal spectra for the microrelief spatial distributions at the Madrid and La Higeruela sites are shown in Fig. 5 and 6 , respectively. The shape of the $f(\alpha)$ curve for the Madrid site is visible proof of the multifractal nature of the SSR in that experimental field (Fig. 5). The substantially smaller amplitude of the two spectra at the other site (Table 3) denotes a less complex structure. Even though a gliding box algorithm was used in the MFA to ensure robust spectra, the MFS for the real and random unstructured data (solid line) with the same SD and average were compared to verify the results. As Fig. 6 shows, the two cannot be differentiated, attesting to the scantly complex and self-similar structure of the La Higueruela soils.

Another factor that differed at the two locations was spectral symmetry, which can be quantified by finding the difference between $f(\alpha)$ values for values of $q$ to the right and left of the peak. This can be ascertained by comparing the values of $f(\alpha)$ for $q=5$ and $q=-5$ (Table 3 ). The appearance of low values left of the peak $q$ signifies that the higher values prevail in spectral complexity. Conversely, low values of $f(\alpha)$ to the right of the peak $q$ indicate that the lower values have a greater bearing on complexity. In the present study, all the Madrid site soils (Fig. 5) followed the former pattern, whereas in the remaining soils (Fig.

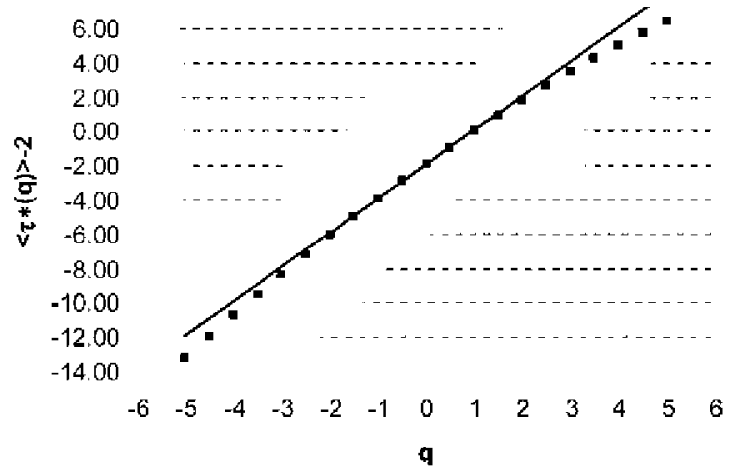

FIG. 4. Plot of the mass exponent function average $\left(\left\langle\tau(q)^{*}\right\rangle-2\right)$ vs. the mass exponent $(q)$ of the soil surface roughness distribution, showing how the moment of mass scales with box size, at the Polytechnic University of Madrid (clay sandy loam texture) after cultivation with a moldboard plow. Symbols represent the original data and the line represents the random data.
6), the pattern of spectral symmetry was similar in the real and random structures.

The similarities in the results for the two La Higueruela soil types reflected the difficulty in moving the ground due to extreme field dryness, particularly in the case of the clayey soil. Nevertheless, the differences observed between the multifractal spectra for the random and real data suggest a possible new approach to quantifying the complexity and hierarchical spatial arrangement of SSR in a given situation. The ratio between spatial height distribution and the respective RD for $\Delta f\left(\alpha_{\text {min }}\right)$ and $w_{\alpha}$ (Table 4) provides a clear description of the scenarios studied. The $\Delta f\left(\alpha_{\text {min }}\right)$ ratio, which denotes structural influence on the highest values of soil roughness, may be interpreted to be a structural index (SI). The $w_{\alpha}$ ratio, which shows the influence of the structure on the local variability of the set studied, is a complexity index (CI).

\section{Discussion and Conclusions}

As an index, SD provides an effective and convenient method for reflecting SSR from the data captured by a pin meter. The lack of a structural component in this sort of analysis is obvious, however.

Fractal and multifractal analyses of SSR data are useful descriptors of SSR structure and complexity and a valuable supplement to statistical indexes such as SD. In all the experiments,
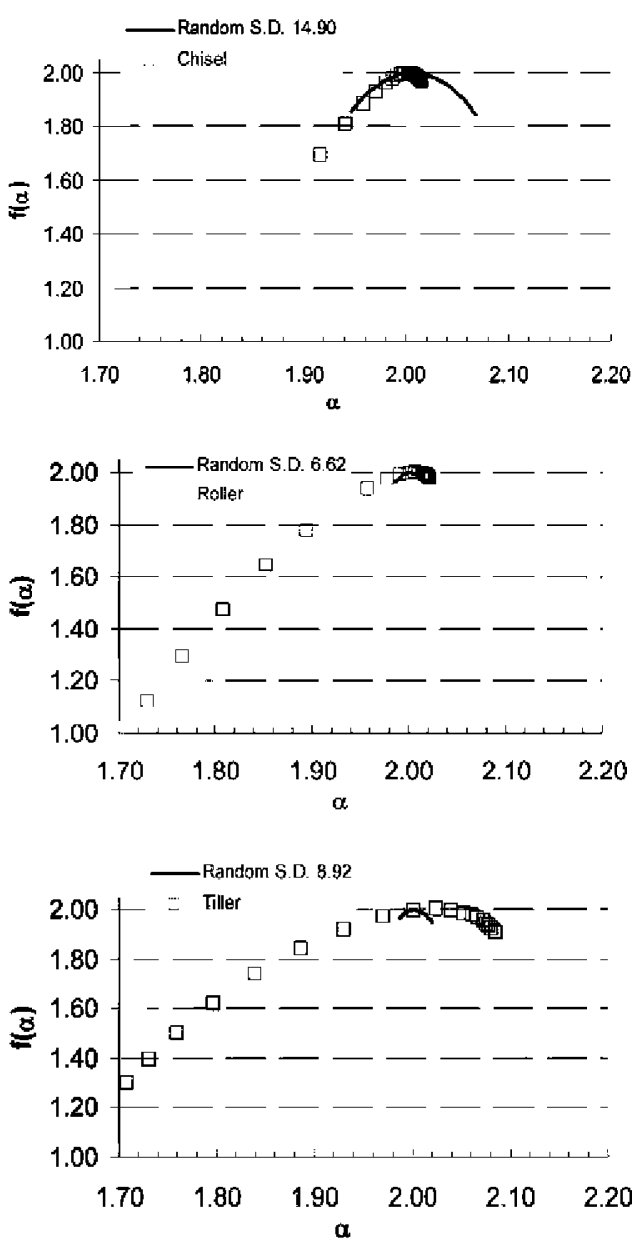

FIG. 5. Multifractal spectrum of soil surface roughness distribution at the Polytechnic University of Madrid site (clay sandy loam texture). Real (symbol) and random (line) data have been used in the multifractal analysis of soil surface roughness for the tillage tools. 
TABLE 3. Multifractal spectrum parameters, including the maximum and minimum values of the singularity index $\left(\alpha_{\max }\right.$ and $\left.\alpha_{\text {min }}\right)$, difference of the scaling exponent of the cells $\alpha_{\max }$ and $\alpha_{\min }\left[\Delta f\left(\alpha_{\max }\right)\right.$ and $\left.\Delta f\left(\alpha_{\min }\right)\right]$, and the multifractal spectrum width $\left(w_{\alpha}\right)$, for spatial height distribution for three tillage treatments and the following soils: a sandy clay loam at Madrid (ST1); a sandy clay loam at La Higueruela (ST2); and a sandy loam at La Higueruela (ST3).

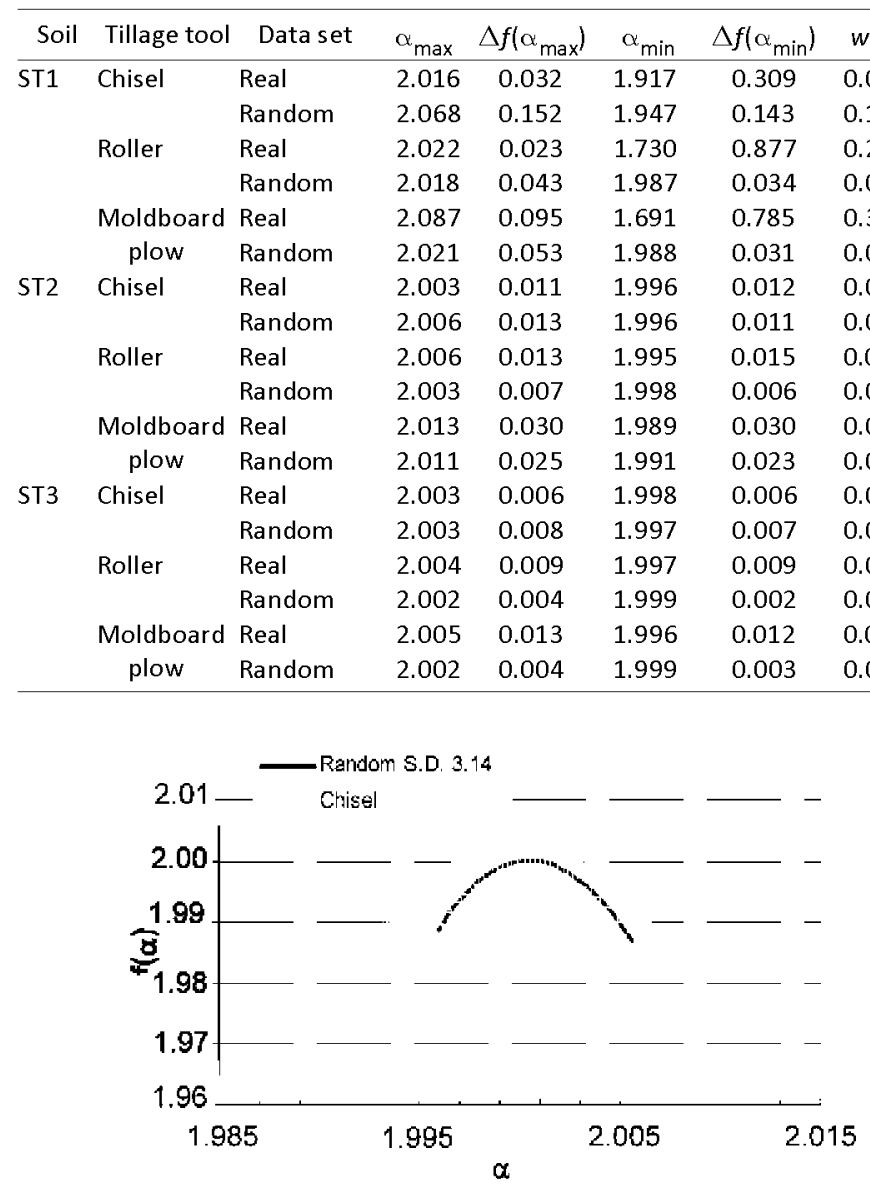
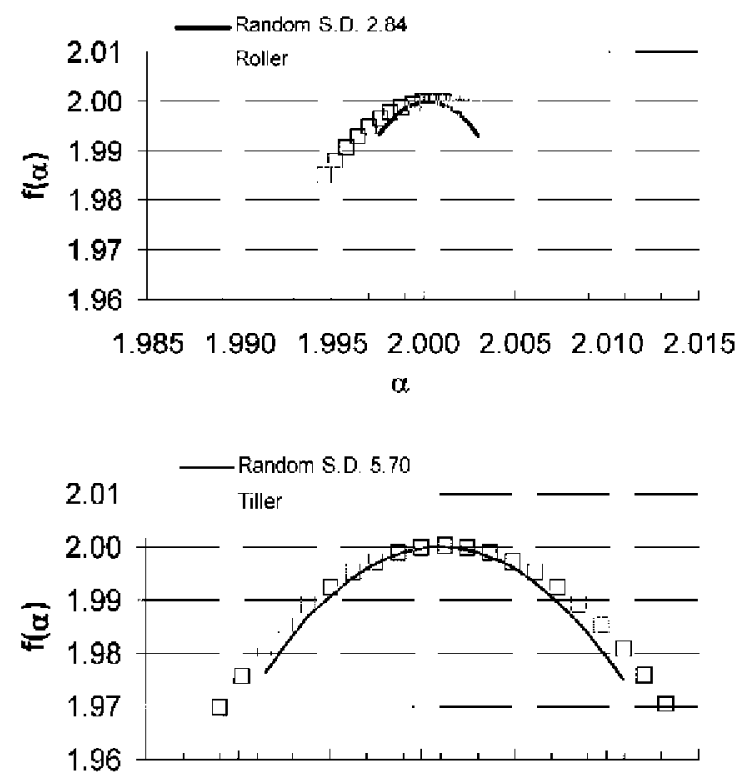

$\begin{array}{lllllll}1.985 & 1.990 & 1.995 & 2.000 & 2.005 & 2.010 & 2.015\end{array}$

$\alpha$
TABLE 4. Ratios of spatial height distribution values to the respective random data set values of the difference of the scaling exponent of the minimum value of the singularity index, $\Delta f\left(\alpha_{\text {min }}\right)$, the multifractal spectrum width, $w_{\alpha}$ the fractal dimension, $D$, the crossover length, I, and the SD for three tillage treatments and the following soil types: a sandy clay loam at Madrid (ST1); a sandy clay loam at La Higueruela (ST2); and a sandy loam at La Higueruela (ST3).

\begin{tabular}{clcrrrr}
\hline Soil & Tillage tool & $\Delta f\left(\alpha_{\min }\right)$ & $w_{\alpha}$ & $D$ & 1 & \multicolumn{1}{c}{ SD } \\
\hline ST1 & Chisel & 2.16 & 0.82 & 2.90 & 274.00 & 16.00 \\
& Roller & 25.79 & 8.59 & 2.90 & 348.00 & 8.90 \\
& Moldboard & 25.32 & 11.97 & 2.90 & 242.00 & 6.60 \\
& plow & & & & & \\
ST2 & Chisel & 1.09 & 0.90 & 2.70 & 160.00 & 3.50 \\
& Roller & 2.50 & 2.20 & 2.90 & 250.00 & 5.90 \\
& Moldboard & 1.30 & 1.26 & 2.50 & 66.00 & 3.00 \\
& $\quad$ plow & & & & & \\
ST3 & $\begin{array}{l}\text { Chisel } \\
\text { Roller }\end{array}$ & 0.86 & 0.83 & 2.50 & 100.00 & 3.30 \\
& 4.50 & 2.33 & 2.60 & 46.00 & 2.42 \\
& Moldboard & 4.00 & 3.33 & 2.70 & 52.00 & 1.87 \\
& plow & & & & & \\
\hline
\end{tabular}
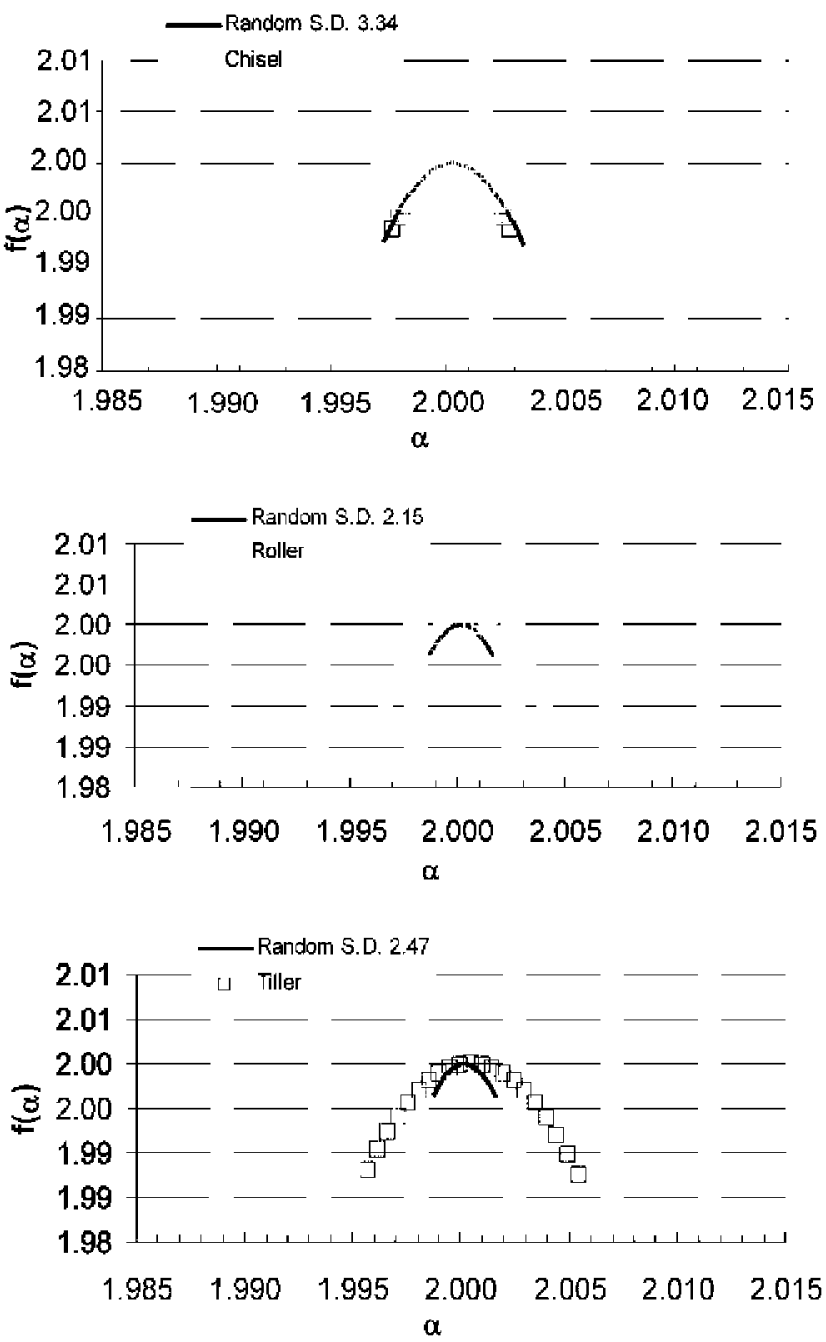

FIG. 6. Multifractal spectrum of soil surface roughness distribution at La Higueruela in a clay sandy loam soil (left) and sandy loam soil (right). Real (symbol) and random (line) data have been used in the multifractal analysis of soil surface roughness for the tillage tools. 
the fractal dimension of SSR calculated from semivariograms $\left(D_{\mathrm{SMV}}\right)$ proved to be antipersistent, with values ranging from 2.4 to 2.9. Soil surface roughness is much more adequately quantified with crossover length $\left(l_{\mathrm{SMV}}\right)$ than with $D_{\mathrm{SMV}}$.

The CVs of the different indices were calculated by tillage tool and soil type to find their sensitivity to these two variables (Fig. $7 \mathrm{~A}$ and $7 \mathrm{~B}$, respectively). The higher the $\mathrm{CV}$, the more sensitive the index to these variables.

As regards variations due to soil type, for roller and moldboard plow tillage, the CVs for SI and CI were substantially higher than for the other indices, whereas for chisel plow tillage, SD exhibited the greatest variation. The latter finding is an indication of the scant complexity of the structure generated by the tool regardless of soil type. Index $D$ was the least sensitive in all cases. Structural index and CI were also the most sensitive to variations in tillage tools, except in the sandy clay loam soil at La Higueruela, where $l$ showed greater sensitivity.

Multifractal analysis is highly sensitive to the spatial arrangement of soil height measurements. It appears to be better suited than conventional indices to comparing differently managed plots. The comparison between SSR data and random spatial arrangement (same average and SD as raw data) provides a sound basis for studying the heterogeneity and complexity of SSR structure via $\Delta f\left(\alpha_{\min }\right)$ and $w_{\alpha}$ ratios.

All the methodologies used showed some correlation to soil textural properties and tillage tools. The SSR values obtained with different tillage tools were higher in clayey soils, where the

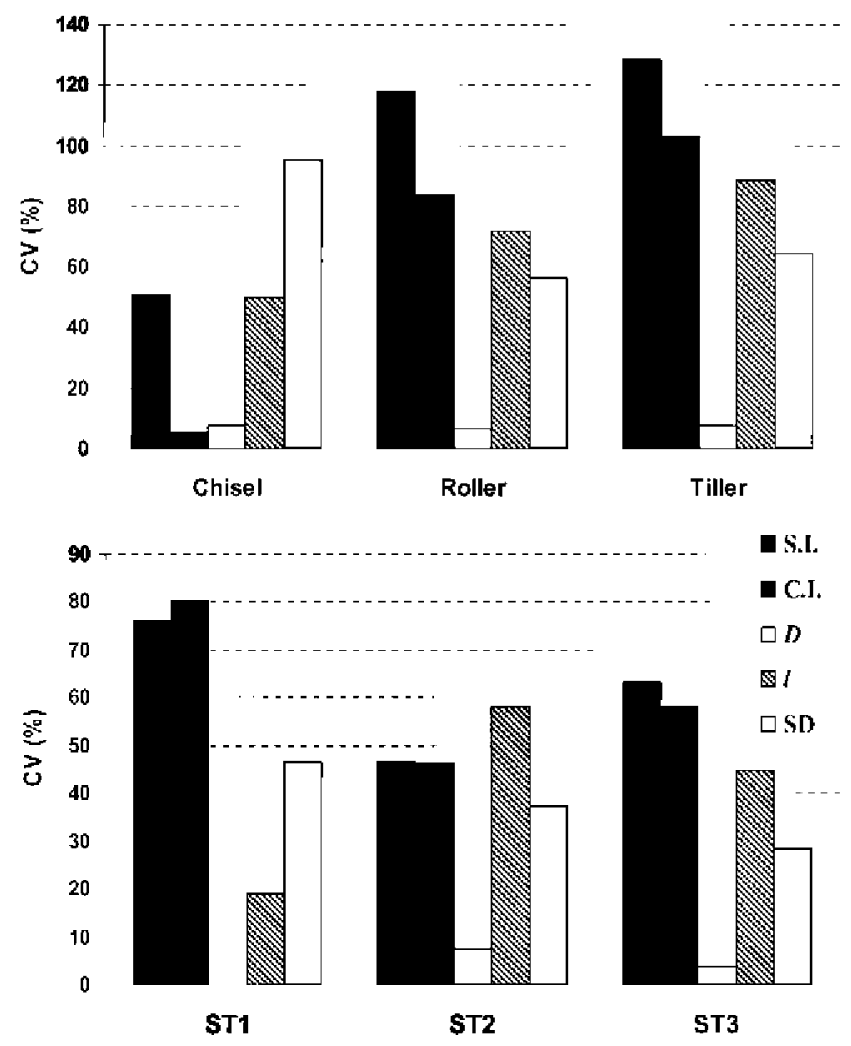

FIG. 7. Coefficients of variation by (A) tillage tool and (B) soil type (a sandy clay loam soil at the Polytechnic University of Madrid [ST1], a sandy clay loam at La Higueruela [ST2], and a sandy loam at La Higueruela [ST3]) using structural index (SI), complexity index (Cl), fractal dimension $(D)$, crossover length $(I)$, and standard deviation (SD). presence of clods and rock fragments adds to heterogeneity, raising the associated indices. Higher SSR was found when plowing was performed with a chisel plow, followed in decreasing order by moldboard plows and rollers. In semiarid soils, conservation tillage appears to conserve SSR homogeneity regardless of the tillage tool used. Since extremely dry soil may affect the results in such regions, however, field problems must be taken into account when interpreting the resulting SSR data.

\section{ACKNOWLEDGMENTS}

We wish to thank Dr. Carlos Lacasta, Director of the Spanish National Research Council's Experimental Centre for Environmental Science at La Higueruela Santa Olalla, Toledo, and his team, as well as the staff of the School of Agricultural Engineering's (Polytechnic University of Madrid) experimental fields, for their cooperation in conducting the field experiments. This study was partially funded by the Regional Government of Madrid and the Polytechnic University of Madrid under Project CCG06-UPM/AGR-22 and by the Spanish Council for Scientific and Technical Research under Project AGL2006-12689/AGR.

\section{References}

Agterberg, F.P., Q. Cheng, A. Brown, and D. Good. 1996. Multifractal modelling of fractures in Lac Du Bonnet batholith, Manitoba. Comput. Geosci. 22:497-507.

Ahammer, H., and T.T.J. DeVaney. 2005. The influence of noise on the generalized dimensions. Chaos Solitons Fractals 26:707-717.

Allain, C., and M. Cloitre. 1991. Characterizing the lacunarity of random and deterministic fractal sets. Phys. Rev. A: Gen. Phys. 44:3552-3558.

Allmaras, R.R., R.E. Burwell, W.E Larson, and R.F. Holt. 1966. Total porosity and random roughness of the interrow zone as influenced by tillage. USDA-ARS Conserv. Res. Rep. 7. U.S. Gov. Print. Office, Washington, DC.

Armstrong, A.C. 1986. On the fractal dimensions of some transient soil properties. J. Soil Sci. 37:641-652.

Bertuzzi, P., G. Raws, and D. Couralt. 1990. Testing roughness indices to estimate soil surface changes due to simulated rainfall. Soil Tillage Res. 17:87-99.

Bird, N., M.C. Díaz, A. Saa, and A.M. Tarquis. 2006. A review of fractal and multifractal analysis of soil pore-scale images. J. Hydrol. 322:211-219.

Buczhowski, S., P. Hildgen, and L. Cartilier. 1998. Measurements of fractal dimension by box-counting: A critical analysis of data scatter. Physica A 252:23-24.

Burg, J. 1967. Maximum entropy spectral analysis. p. 34-41. In Proc. Meet. Soc. of Exploration Geophys., 37th, Oklahoma City, OK. 31 Oct. 1967. Soc. Explor. Geophys., Tulsa, OK.

Burrough, P.A. 1983. Multiscale source of spatial variation in soil: I. The application of fractal concepts to nested levels of soil variation. J. Soil Sci. 34:577-597.

Cheng, Q. 1997a. Discrete multifractals. Math. Geol. 29:245-266.

Cheng, Q. 1997b. Multifractal modeling and lacunarity analysis. Math. Geol. 29:919-932.

Cheng, Q. 1999. The gliding box method for multifractal modeling. Comput. Geosci. 25:1073-1079.

Cheng, Q., and F.P. Agterberg. 1996. Multifractal modeling and spatial statistics. Math. Geol. 28:1-16.

Currence, H.D., and W.G. Lovely. 1970. The analysis of soil surface roughness. Trans. ASAE 13:710-714.

Darboux, F., and C.-H. Huang. 2003. An instantaneous-profile laser scanner to measure soil surface microtopography. Soil Sci. Soc. Am. J. 67:92-99.

Eltz, F.L.F., and L.D. Norton. 1997. Surface roughness changes as affected by rainfall erosivity, tillage, and canopy cover. Soil Sci. Soc. Am. J. 61:17461755.

Evertsz, C.J.G., and B.B. Mandelbrot. 1992. Multifractal measures. p. 921-953. In H. Peitgen et al. (ed.) Chaos and fractals. Springer-Verlag, Berlin.

Feder, J. 1989. Fractals. Plenum Press, New York.

Gallant, J.C., I.D. Moore, M.F. Hutchinson, and P. Gessler. 1994. Estimating fractal dimension of profiles: A comparison of methods. Math. Geol. 26:455-481.

Gallart, F., and G. Pardini. 1996. Perfilru: Un programa para el análisis de per- 
files microtopograficos mediante el estudio de la geometría fractal. (In Spanish.) Cuad. Lab. Xeolóxico de Laxe 21:169-178.

García Moreno, R. 2006. Desarrollo de una metodología para la medición de la rugosidad del suelo. Ph.D. diss. Univ. Politécnica de Madrid, Madrid.

Grau, J., V. Médez, A.M. Tarquis, A. Saa, and M.C. Díaz. 2006. Comparison of gliding box and box-counting methods in soil image analysis. Geoderma 134:349-359.

Hagen, L.J. 1988. New wind erosion model developments in the USDA. p. 104116. In 1988 Wind Erosion Conf. Proc., Lubbock, TX. 11-13 Apr. 1988. Texas Tech, Univ., Lubbock.

Huang, C.H. 1998. Quantification of soil microtopography and surface roughness. p. 153-168. In P. Baveye et al. (ed.) Fractals in soil science. Advances in soil science. CRC Press, Boca Raton, FL.

Huang, C.H., and J.M. Bradford. 1992. Applications of a laser scanner to quantify soil microtopography. Soil Sci. Soc. Am. J. 56:14-21.

Kamphorst, E.C., V. Jetten, J. Guérif, J. Pitkänen, B.V. Iversen, J.T. Douglas, and A. Paz. 2000. Predicting depressional storage from soil surface roughness. Soil Sci. Soc. Am. J. 64:1749-1758.

Larney, F.J., M.S. Bullock, H.H. Janzen, B.H. Ellert, and E.C.S. Olson. 1998. Wind erosion effects on nutrient redistribution and soil productivity. J. Soil Water Conserv. 53:133-140.

Larney, F.J., M.S. Bullock, S.M. McGinn, and D.W. Fryrear. 1995. Quantifying wind erosion on summer fallow in southern Alberta. J. Soil Water Conserv. 50:91-95.

Larney, F.J., A.J. Cessna, and M.S. Bullock. 1999. Long-term wind erosion hazard of wheat-fallow cropping. Soil Sci. Soc. Am. J. 63:1768-1777.

Linden, D.R., and D.M. Van Doren, Jr. 1986. Parameters for characterizing tillage-induced soil surface roughness. Soil Sci. Soc. Am. J. 50:1550-1565.

Malinverno, A. 1990. A single method to estimate the fractal dimension of selfaffine series. Geophys. Res. Lett. 17:1953-1956.

Manninen, A.T. 2003. Multiscale surface roughness description for scattering modelling of bare soil. Physica A 319:535-551.

Merel, A.P., and P.J. Farres. 1998. The monitoring of soil surface development using analytical photogrammetry. Photogramm. Record 16:331-345.

Merrill, S. 1995. Procedures for soil analysis. Int. Soil Ref. and Inf. Ctr., Wageningen, the Netherlands.

Murillo, J.M., E. Moreno, I.F. Girón, and M.I. Oblitas. 2004. Conservation tillage: Long term effect on soil and crops under rainfed conditions in southwest Spain (western Andalusia). Span. J. Agric. Res. 2:35-43.

Pardini, G., and F.A. Gallart. 1998. Combination of laser technology and fractals to analyze soil surface roughness. Eur. J. Soil Sci. 49:197-202.

Perfect, E., P.H. Groenevelt, B.D. Kay, and C.D. Grant. 1990. Spatial variability of soil penetrometer measurements at the mesoscopic scale. Soil Tillage Res. 16:257-271.

Perfect, E., and B.D. Kay. 1995. Applications of fractals in soil and tillage research: A review. Soil Tillage Res. 36:1-20.

Perrier, E., A.M. Tarquis, and A. Dathe. 2006. A program for fractal and multifractal analysis of two-dimensional binary images: Computer algorithms versus mathematical theory. Geoderma 134:284-294.

Pike, R.J. 2000. Geomorphometry-diversity in quantitative surface analysis. Phys. Geogr. 24:1-20.

Podmore, T.H., and L.F. Huggins. 1981. An automated profile meter for surface roughness measurements. Trans. ASAE 24:663-665, 669.

Porta Casanellas, J., M. López-Acevedo Reguerín, and C. Roquero de Laburu. 2003. Edafología para la agricultura y el medio ambiente. Mundi-Prensa, Madrid.

Potter, K.N., T.M. Zobeck, and L.J. Hagen. 1990. A microrelief index to estimate soil erodibility by wind. Trans. ASAE 33:151-155.

Roisin, C.J.C. 2007. A multifractal approach for assessing the structural state of tilled soils. Soil Sci. Soc. Am. J. 71:15-25.

Saxton, K.E. 1995. Wind erosion and its impact on off-site air quality in the Columbia plateau: An integrated research plan. Trans. ASAE 38:1031-1038.

Schertzer, D., and S. Lovejoy. 1991. Nonlinear variability in geophysics. Kluwer Academic Publ., Dordrecht, the Netherlands.

Sparks, D.L. (ed.). 1996. Methods of soil analysis: Part 3. Chemical methods. SSSA Book Ser. 5. SSSA, Madison, WI.

Tarquis, A.M., D. Giménez, A. Saa, M.C. Diaz, and J.M. Gascó. 2003. Scaling and multiscaling of soil pore systems determined by image analysis. p. 19-34. In Ya. Pachepsky et al. (ed.) Scaling methods in soil physics. CRC Press, Boca Raton, FL.
Tarquis, A.M., J.C. Losada, R. Benito, and F. Borondo. 2001. Multifractal analysis of the Tori destruction in a molecular Hamiltonian system. Phys. Rev. E 65(1):0126213; doi:10.1103/PhysRevE.65.016213.

Vidal Vázquez, E., J.G.V. Miranda, M.C. Alves, and A. Paz González. 2006. Effect of tillage on fractal indices describing soil surface microrelief of a Brazilian Alfisol. Geoderma 134:428-439.

Vidal Vázquez, E., J.G. Vivas Miranda, and A. Paz Gónzalez. 2005. Characterizing anisotropy and heterogeneity of soil surface microtopography using fractal models. Ecol. Modell. 182:337-353.

Vidal Vázquez, E., J.G.V. Miranda, and A. Paz González. 2007. Describing soil surface microrelief by crossover length and fractal dimension. Nonlinear Processes Geophys. 14:223-235.

Vivas Miranda, J.G. 2000. Análisis fractal del microrrelieve del suelo. (In Spanish.) Ph.D. diss. Univ. da Coruña, A Coruña, Spain.

Vivas Miranda, J.G., and A. Paz González. 2002. Fractal models for the description of soil surface roughness. p. 2099-2112. In J.L. Rubio et al. (ed.) Proc. Int. Congr. Man and Soil at the Third Millennium, 3rd, Valencia, Spain. 28 Mar. -31 Apr. 2000. Geoforma Ediciones, Logroño, Spain.

Zobeck, T.M. 1991. Soil properties affecting wind erosion. J. Soil Water Conserv. 46:112-118.

Zobeck, T.M., and C.A. Onstad. 1987. Tillage and rainfall effect on random roughness: A review. Soil Tillage Res. 9:1-20. 